\title{
Potential of Vigna unguiculata as a Phytoremediation Plant in the Remediation of Zn from Contaminated Soil
}

\author{
Jyotsana Singh*, Padmalochan Hembram*, Jolly Basak\# \\ Department of Biotechnology, Visva-Bharati, Santiniketan, India \\ Email: "iolly.basak@visva-bharati.ac.in
}

Received 20 January 2014; revised 3 March 2014; accepted 19 March 2014

Copyright (C) 2014 by authors and Scientific Research Publishing Inc.

This work is licensed under the Creative Commons Attribution International License (CC BY). http://creativecommons.org/licenses/by/4.0/

\section{Abstract}

Population explosion in the last decades together with global industrialization has caused heavymetal contamination of air, water and soil, resulting in diverse incurable effects on humans and on the stability of the ecosystem. Non-biodegradable heavy-metals can remain in the ecosystem and the threat associated with their bioaccumulation in food chains represents one of the major environmental and health problems of present day society. Several studies were carried out to understand the ecological effects of the heavy-metal $\mathrm{Zn}$ in soil-plant systems. Plants often have a zinc uptake that their systems cannot handle, due to the accumulation of zinc in soils. Of the several $\mathrm{Zn}$ toxicity symptoms, fatal are yield reduction, stunted growth, chlorosis, reduced chlorophyll synthesis and chloroplast degradation. Vigna unguiculata is an herbaceous, annual plant in the pea family Fabaceae. In the present study, an experiment was performed to evaluate the Zn phytoextracting ability of $V$. unguiculata under in vitro condition. We establish that $V$. unguiculata can uptake a considerable amount of the heavy-metal zinc and this phytoextraction property can be utilized in long run for the cleanup of zinc contaminated soil. To the best of our knowledge, this is the first report of $\mathrm{Zn}$ phytoextraction ability of $V$. unguiculata.

\section{Keywords}

Heavy-Metal Toxicity; Phytoremediation; Proline; Atomic Absorption; Vigna unguiculata

\section{Introduction}

Population explosion in the last few decades together with global industrialization has caused heavy metal con-

${ }^{*}$ The authors contributed equally to the paper.

${ }^{*}$ Corresponding author.

How to cite this paper: Singh, J., Hembram, P. and Basak, J. (2014) Potential of Vigna unguiculata as a Phytoremediation Plant in the Remediation of Zn from Contaminated Soil. American Journal of Plant Sciences, 5, 1156-1162. 
tamination of air, water and soil, resulting in diverse incurable effects on humans and also on the stability of the ecosystem. Heavy metals due to their non-biodegradable property can remain in the ecosystem for a long time. Heavy metal toxicity and the threat associated with their bioaccumulation in food chains represent one of the major environmental and health problems of our present day society.

Several studies has been carried out to understand the ecological effects of the heavy metal $\mathrm{Zn}$ in soil-plant systems, which indicated that plant yield decreases due to a toxic effect of Zn on the ecosystem [1]-[4]. Plants often have a zinc uptake that their systems cannot handle, due to the accumulation of zinc in soils. Elevated levels of $\mathrm{Zn}$ in soils contaminated by mining and smelting activities, in agricultural soils treated with sewage sludge, and in urban and peri-urban soils enriched by anthropogenic inputs of $\mathrm{Zn}$ is the major cause of $\mathrm{Zn}$ toxicity in plants [5] [6]. Zn toxicity symptoms include reduced yields and stunted growth, Fe-deficiency-induced chlorosis through reductions in chlorophyll synthesis and chloroplast degradation, and interference with $\mathrm{P}, \mathrm{Mg}$ and $\mathrm{Mn}$ uptake [5]-[9]. In humans, reports of Zn-toxicity have been mostly in response to food poisoning incidents. Effects of long-term, excessive zinc intakes (ranging from $150 \mathrm{mg}$ /day to 1 - 2 g/day) include nausea and vomiting, hypochromic anaemia, leukopenia, epigastric pain, abdominal cramps, and diarrhea [10] [11].

The current state-of-the-art technology for the clean-up of toxic metal-contaminated soils includes physical remediation, chemical remediation and phytoremediation [12]-[14]. The limitations of first two methods are high cost, destruction of soil structures and had an adverse effect on biological life. The development of phytoremediation technique is being driven primarily by the high cost of many other remediation methods, as well as the desire to use green, sustainable process [15]. Phytoremediation is environmental friendly method which utilizes the uptake ability of plants for the removal of heavy metals from the soil-water environment. Phytoremediation is basically an assemblage of four different techniques, namely, rhizofiltration, which employ plants to clean various aquatic environments; phytostabilization, where plants are used to stabilize contaminated soil; phytovolatilization, where plants extract specific metals from soil and then release them into the atmosphere through volatilization; and phytoextraction, where plants extract metals from soil and translocate them to the shoots where they accumulate [16]. The two terms, phytoremediation and phytoextraction, are sometimes used as synonyms; however, phytoremediation is a concept while phytoextraction is a definite cleanup technology [16].

Vigna unguiculata is a herbaceous, annual plant in the pea family Fabaceae. The domestication of vigna unguiculata was originated in West Africa. It is one of the most widely used legumes in the semiarid tropics including Asia, Africa, southern Europe and Central and South America. Hundreds of experiments have been conducted on this legume to understand its morphology, physiology, as well as to understand the effect of different stresses on this legume. However, only a scanty number of experiments have been carried out to study the $\mathrm{Zn}$ phytoextracting ability of $V$. unguiculata [17]. In the present study, an experiment was performed to evaluate the $Z n$ phytoextracting ability of $V$. unguiculata under in vitro condition. We establish that $V$. unguiculata can uptake a considerable amount of the heavy metal zinc and this phytoextraction property can be utilized in long run for the cleanup of zinc contaminated soil. To the best of our knowledge, this is the first report on the study of the $\mathrm{Zn}$ phytoextraction ability of $V$. unguiculata.

\section{Materials and Methods}

\subsection{Plant Material and Treatments}

Seeds of Vigna unguiculata var. unguiculata were surface sterilized in $0.1 \% \mathrm{HgCl}_{2}$ solution and washed with distilled water prior to germination. Equal numbers of seeds were germinated in experimental pots in triplicates containing half strength Hoagland solution as a nutrient media at controlled temperatures. The basic composition in the growth medium includes N, K, Ca, P, S, Mg, B, Fe, Mn, Zn, Cu, and Mo. Five days old seedlings were stressed with the heavy metal $\mathrm{Zn}$ at the concentration of $250 \mu \mathrm{M}$ and $500 \mu \mathrm{M}$, respectively. The stated metal concentrations were added from the stock solutions of analytical grade heavy metal salts $\left(\mathrm{ZnSO}_{4.7} \mathrm{H}_{2} \mathrm{O}\right)$ prepared in distilled water. Plants grown on medium without heavy metals constituted the control. Experiments lasted for 15 days, during which period the plants were harvested at 3rd, 6th, 9th, 12 th and $15^{\text {th }}$ day after the initiation of treatment. After harvesting, half of the sample amount was used for determining morphological parameters and proline accumulation and the other half was used to study the $\mathrm{Zn}$ uptake. To study the metal uptake, each plant was separated into leaf portions and combined root-stem portions and metal uptake was measured from each portion separately. 


\subsection{Growth Parameters}

Two parameters were measured; plant height and total fresh weight. These parameters were measured at 3rd, 6th, 9th, 12th and 15th day, after initiation of the treatment. Plant heights were measured with a metre tape from the root tip to the apex of the plant. The fresh weights were obtained by uprooting the plant from medium and weighed on a weighing balance immediately after harvest to avoid water loss.

\subsection{Proline Estimation}

Proline content was determined following the method of Bates [18]. One gm of tissue was homogenized in 10 $\mathrm{ml}$ of sulfosalicylic acid (3\%) and centrifuged at $4000 \mathrm{rpm}$ for $10 \mathrm{mins}$. About $2 \mathrm{ml}$ of extract supernatant was taken in a test tube and to it $2 \mathrm{ml}$ of glacial acetic acid and $2 \mathrm{ml}$ of ninhydrin reagent was added. The reaction mixture was boiled in water bath at $100^{\circ} \mathrm{C}$ for 30 minutes. After cooling the reaction mixture, 4 ml of toluene was added and vortex for 30 seconds. The upper phase containing proline was measured with spectrophotometer at $520 \mathrm{~nm}$ using toluene as a blank. Proline content ( $\mu \mathrm{mol}$ g-1 fr. wt.) was quantified using the ninhydrin acid reagent method by using L-proline as a standard.

\subsection{Zinc Accumulation}

Harvested plants were thoroughly washed in distilled water. Leaves and combined root-stem were separated and oven dried at $80^{\circ} \mathrm{C}$ for 24 hours. Oven dried samples were grounded into fine powder and kept in a mixture of percholoric acid and nitric acid (1:5) for overnight. Next day, samples were digested in water bath at $80^{\circ} \mathrm{C}$ for 1 hour, filtered and the clear filtrate was taken. The volume of filtrate was increased to $15 \mathrm{ml}$ with distilled water. Total $\mathrm{Zn}$ concentration in the samples was then determined by hydride generation atomic absorption spectrophotometer (AA 6800, Shimadzu). Zn from $\mathrm{ZnSO}_{4}$ was used as for calibration.

\section{Results and Discussion}

\subsection{Statistical Analysis of the Data}

Each of the three experiments for measurement of growth parameters (plant height and total fresh weight), estimation of proline content and estimation of Zn accumulation were done in triplicates. From individual experiments, the obtained data were statistically analyzed by calculating the standard deviation and error bars based on the standard deviations.

\subsection{Phytotoxic Effects of Zn on Plant Height and Plant Weight}

Figure 1 and Figure 2 shows the variation of plant heights and plant weights in treated and control plants at different Zn concentrations, respectively. With enhancing external $\mathrm{Zn}$ concentrations, the lengths of the treated seedlings were decreased in comparison to the controls. Maximum decrease (26.8\%) was recorded for 15 days old seedlings at $500 \mu \mathrm{M} Z \mathrm{Zn}$ stress (Figure 1). There are reports that Zn stress causes multiple direct and indirect effects on plant growth by disrupting metabolic processes [19]-[21]. Zn accumulation in cell wall components, especially pectic substances and hemicelluloses, reduces the frequency of mitosis with a direct consequence in the decrease of plant height [22]. In the present study, the reduced height and weakly developed root systems of the $V$. unguiculata Zn-treated seedlings compare to the controls, at increasing Zn concentration were due to such effects of the heavy metal Zn on the growing seedlings. Similar results were observed while considering total plant weight. Total weight of the treated seedlings with respect to the controls decreased with enhancing external Zn concentration. Maximum decrease (16.7\%) was observed in 15 day old seedlings under $500 \mu \mathrm{M}$ Zn stress (Figure 2). Earlier investigations showed that the heavy metals chromium, cadmium, manganese, lead and nickel [17] [23]-[25] reduces the leaf area; consequently total weight of the plant reduces. In this study, the reduced weight of the Zn- treated seedlings can be attributed to either a reduction in the number of cells or due to reduction in cell size. Zn-treated plants spent more energy for their survival in the hostile environment, which otherwise would be available for their overall growth processes, resulting in a reduced height and weight. However, we found that the Zn-treated plants, with the reduced height and weakly developed root systems, withstand the $\mathrm{Zn}$ stress and the overall vigor of the treated plants was not that affected compare to the control plants, indicating that $V$. unguiculata plants can accumulate the heavy metal $\mathrm{Zn}$. 


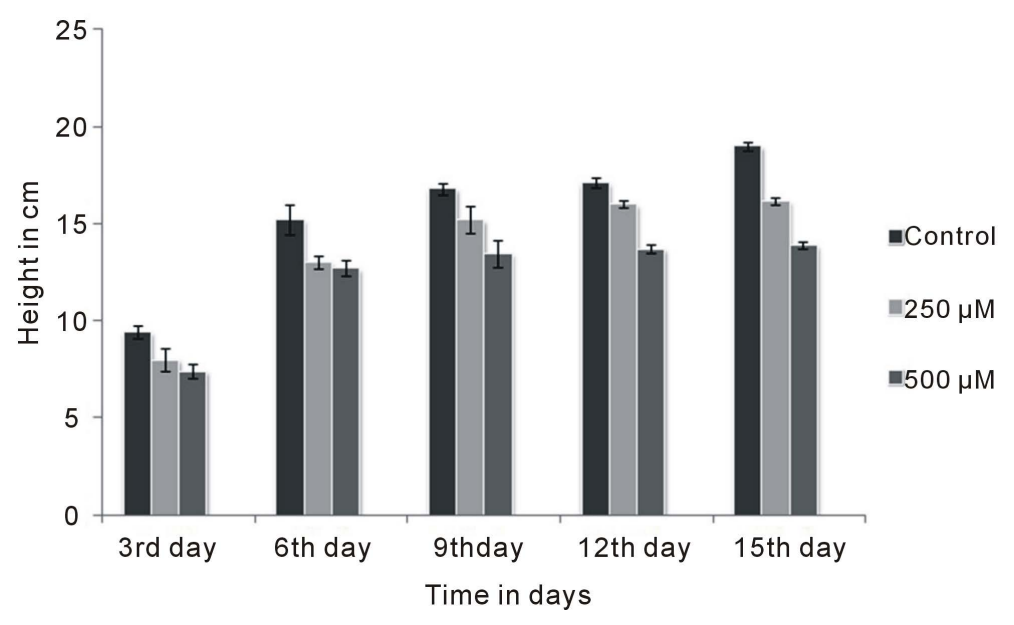

Figure 1. Variation of plant heights in treated and control plants at different Zn concentrations..

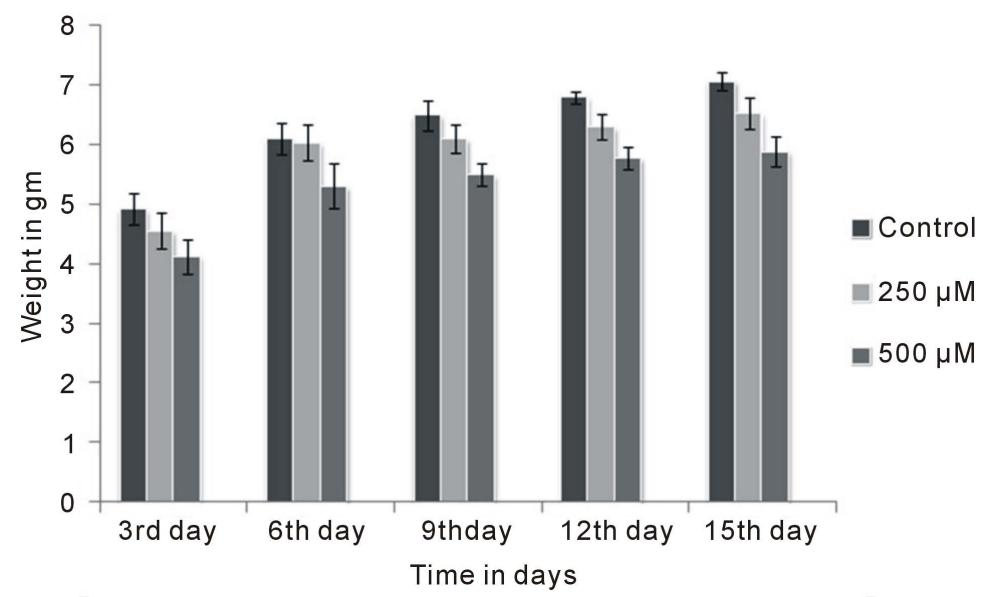

Figure 2. Variation of plant weights in treated and control plants at different Zn concentrations.

\subsection{Changes in Proline Content Accompanying Zn Uptake}

Results showed that the proline accumulation in treated seedlings increased with increasing Zn concentration and was highest (59\%) under $500 \mu \mathrm{M}$ Zn stress of 15 days old seedlings (Figure 3). Accumulation of stress marker proline in treated plants is an indicator of primary defense response to maintain the osmotic pressure in cells. Several reports show a significant role of proline in osmotic adjustment, protecting cell structure and its function in plants and cultivars of many crops [26] [27]. Proline accumulates in many plant species under a broad range of abiotic stresses as water shortage, salinity, extreme temperatures, and heavy metal accumulation [28]-[31] as well as under biotic stresses [32] [33]. At the structural level, proline protects folded protein structures against denaturation by functioning as a hydroxyl radical scavenger and also stabilizes cell membranes by interacting with phospholipids. In the present study, increasing amount of heavy metal Zn concentration in treated seedlings exerted increased amount of stress, which in turn increased the amount of osmoprotectant proline content. Nevertheless, Zn treated plants with increased amount of stress marker proline survived well, indicating that $V$. unguiculata plants can accumulate the heavy metal $\mathrm{Zn}$.

\subsection{Effect of Different Treatment of Zn Concentrations on Accumulation of This Heavy Metal}

Uptake of Zn by $V$. unguiculata seedlings under two different concentrations of externally added Zn has been 
conducted in hydroponic medium under in vitro condition for a period of 15 days (Figure 4 \& Figure 5). The significant increase in the level of $\mathrm{Zn}$ in root-stem and leaves was in accordance with the increase in external $\mathrm{Zn}$ treatment. Uptake of $\mathrm{Zn}$ was found more in root-stem system than leaves of $V$. unguiculata seedlings. The maximum Zn uptake of $409 \mu \mathrm{g}$ g- 1 dry wt in root-stem system was found in 15 day old seedlings under $500 \mu \mathrm{M}$ Zn stress. Uptake of $369 \mu \mathrm{g} Z n$ per gm dry wt in leaves was found in 15 day old seedlings under $500 \mu \mathrm{M} \mathrm{Zn}$ stress. Although $V$. unguiculata seedlings accumulated a considerable amount of the heavy metal Zn within the span of 15 days experiment, yet, overall vigor of the seedlings were not that affected with respect to the control plants, indicating that $V$. unguiculata can accumulate the heavy metal $\mathrm{Zn}$ in its roots and shoots. However, we did not find and $\mathrm{Zn}$ accumulation in the seeds of $V$. unguiculata (unpublished results).

The phytoextraction technology, to be fully effective, depends upon several plant characteristics. The two most significant characters include the ability to rapidly accumulate considerable amount of biomass and the ability to accumulate considerable amount of heavy metals within the shoot tissue [34]. It is the combination of both high biomass production and considerable amount of heavy metal accumulation that results in the success of this technology. Present study showed that, $V$. unguiculata being a rapid accumulator of biomass is also efficient at translocating the heavy metal $\mathrm{Zn}$ from ground to the harvestable above-ground portions of the plant andcan tolerate $409 \mu \mathrm{g}$ g- 1 dry wt of the heavy metal Zinc. Although, the amount of $\mathrm{Zn}$ accumulation by $V$. Un-guiculata does not define it as a hyperaccumulator as per previous report [35] yet its accumulation of a considerable amount of the heavy metal Zn makes it a potential candidate as a phytoremediation plant in the reme-

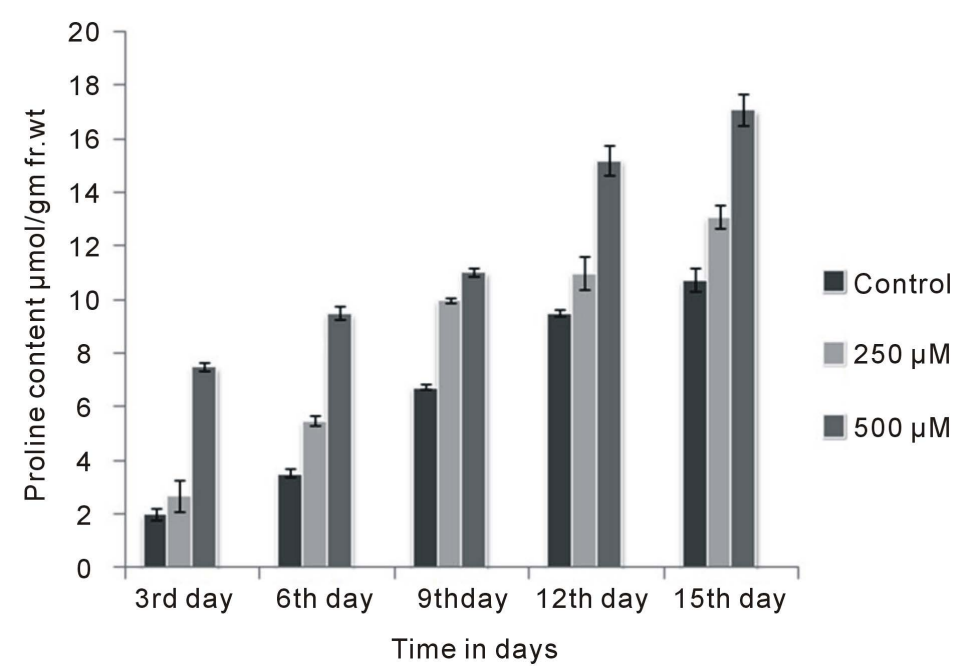

Figure 3. Proline accumulation in treated and control plants at different $\mathrm{Zn}$ concentrations.

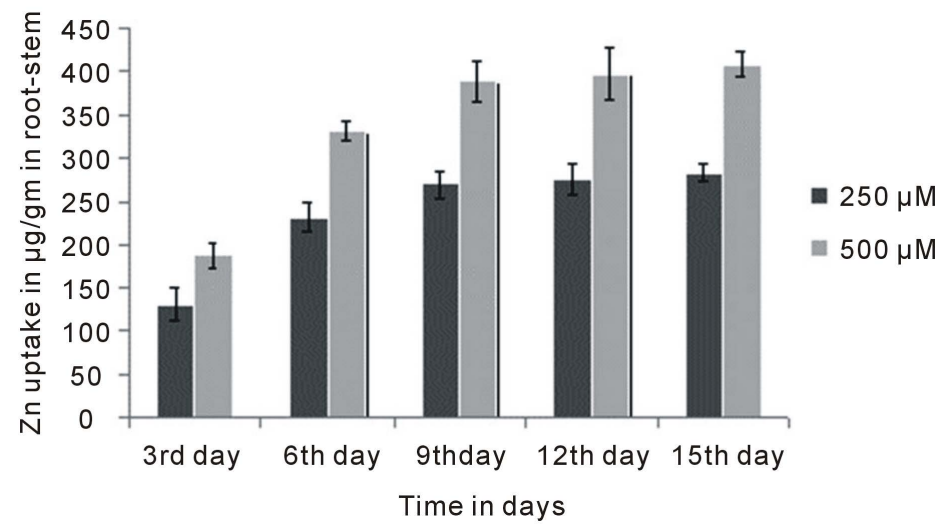

Figure 4. Zn uptake in root-stem portion of treated plants at different $\mathrm{Zn}$ concentration. 


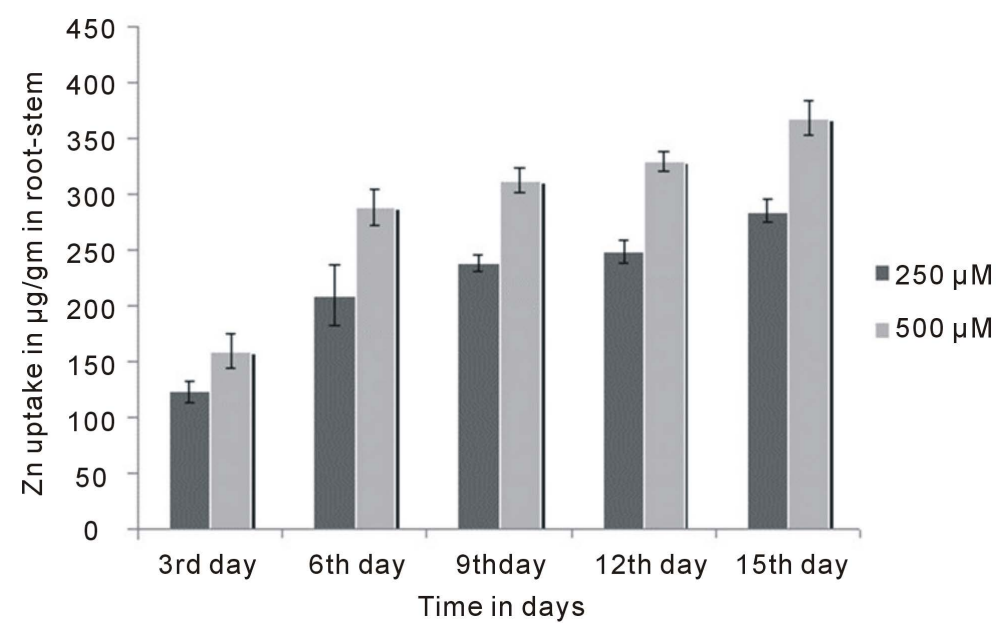

Figure 5. Zn uptake in leaves of treated plants at different Zn concentration.

diation of $\mathrm{Zn}$ from contaminated soil. To the best of our knowledge this is the first report on the study of the $\mathrm{Zn}$ phytoextraction ability of $V$. unguiculata.

\section{References}

[1] Zheng, W.J., Zheng, F.Z., Lian, Y.W. and Lin, P. (1996) Accumulation and Dynamics of Cu. Pb, Zn and Mn Elements in Kandelia candel (L.) Druce Mangrove Community of Jiulong River Estuary of Fujian. Acta Botanica Sinica, 38, 227-233.

[2] Lorenz, S.E., Hamon, R.E., Holm, P.E., Domingues, H.C., Sequeira, E.M. and Christensen, T.H. (1997) Cadmium and Zinc in Plants and Soil Solutions from Contaminated Soils. Plant Soil, 189, 21-31. http://dx.doi.org/10.1023/A:1004214923372

[3] Wu, Y.Y., Wang, X., Liang, R.L., Wu, T.Z., Xie, Y.K. and Li, S.G. (1997) Ecological Effect of Compound Pollution of Heavy Metals in Soil-Plant System: I. Effect on Crop, Soil Microorganism, Alfalfa and Tree. Chinese Journal of Applied Ecology, 8, 207-212.

[4] Murray, P., Ge, Y. and Hendershot, W.H. (2000) Evaluating Three Trace Metal Contaminated Sites: A Field and Laboratory Investigation. Environmental Pollution, 107, 127-135. http://dx.doi.org/10.1016/S0269-7491(99)00120-7

[5] Chaney, R.L. (1983) Plant Uptake of Inorganic Waste Constituents. In: Parr, J.F., Marsh, P.B. and Kla, J.M., Eds., Land Treatment of Hazardous Wastes, Noyes Data Corporation, Park Ridge, 50-76.

[6] Broadley, M.R., White, P.J., Hammond, J.P., Zelko, I. and Lux, A. (2007) Zinc in Plants. New Phytology, 173, 677-702. http://dx.doi.org/10.1111/j.1469-8137.2007.01996.x

[7] Carroll, M.D. and Loneragan, J.F. (1968) Response of Plant Species to Concentrations of Zinc in Solution. I. Growth and Zinc Content of Plants. Australian Journal of Agricultural Research, 19, 859-868. http://dx.doi.org/10.1071/AR9680859

[8] Boawn, L.C. and Rasmussen, P.E. (1971) Crop response to Excessive Zinc Fertilization of Alkaline Soil. Agronomy Journal, 63, 874-876. http://dx.doi.org/10.2134/agronj1971.00021962006300060015x

[9] Foy, C.D., Chaney, R.L. and White, M.C. (1978) The Physiology of Metal Toxicity in Plants. Annual Review of Plant Physiology, 29, 511-566. http://dx.doi.org/10.1146/annurev.29.060178.002455

[10] Fosmire, G.J. (1990) Zinc Toxicity. American Journal of Clinical Nutrition, 51, 225-227.

[11] Nriagu, J. (2007) Zinc Toxicity in Humans. Elsevier Publication, 1-7.

[12] Zhou, Q.X. and Song, Y.F. (2004) Remediation of Contaminated Soils: Principles and Methods. Science Press, Beijing.

[13] Karami, A. and Shamsuddin, Z.H. (2010) Phytoremediation of Heavy Metals with Several Efficiency Enhancer Methods. African Journal of Biotechnology, 9, 3689-3698.

[14] Raskin I., Smith, R.D. and Salt, D.E. (1997) Phytoremediation of Metals: Using Plants to Remove Pollutants from the Environment. Current Opinion in Biotechnology, 8, 221-226. http://dx.doi.org/10.1016/S0958-1669(97)80106-1

[15] Pulford, L.D. and Watson, C. (2003) Phytoremediation of Heavy Metal-Contaminated Land by Trees-A Review. In- 
ternational Journal of Environment, 29, 529-540. http://dx.doi.org/10.1016/S0160-4120(02)00152-6

[16] Prasad, M.N.V. (2003) Metal Hyperaccumulation in Plants-Biodiversity Prospecting for Phytoremediation Technology. Electronic Journal of Biotechnology, 6, 1-25. http://dx.doi.org/10.2225/vol6-issue3-fulltext-6

[17] Tanee, F.B.G. and Akonye, L.A. (2009) Effectiveness of Vigna unguiculata as a Phytoremediation Plant in the Remediation of Crude Oil polluted Soil for Cassava (Manihot esculenta; Crantz) Cultivation. Journal of Applied Science and Environmental Management, 13, 43-47.

[18] Bates, L.S., Waldren, R.P. and Teare, L.D. (1973) Rapid Determination of Free Proline for Water Stress Studies. Plant and Soil, 39, 205-207. http://dx.doi.org/10.1007/BF00018060

[19] Pahlsson, A.B. (1989) Toxicity of Heavy Metals (Zn, Cu, Cd, Pb) to Vascular Plants. Water Air Soil Pollution, 47, 287-319. http://dx.doi.org/10.1007/BF00279329

[20] Dinev, N. (1988) Effects of Heavy Metals (Cu, Zn, Cd) on the Growth of Oat Plant. Soil Science and Agrochemical. Ecology, 33, 5-9.

[21] Breckle, S.W. (1991) Growth under Stress: Heavy Metal. In: Plant Roots: The Hidden Half, Marcel Dekker, New York, 351-373.

[22] Casey, C.E. and Hambidge, K.M. (1980) Epidemiological Aspects of Human Zinc Deficiency. In: J. O. Nriagu, Ed., Zinc in the Environment, Part II: Health Effects, John Wiley, New York,

[23] Khan, D.H. and Frankland, B. (1983) Effects of Cadmium and Lead on Radish Plants with Particular Reference to Movement of Metals through Soil Profile and Plant. Plant Soil, 70, 335-345. http://dx.doi.org/10.1007/BF02374890

[24] Setia, R.C. and Kaila, J. and Malik, C.P. (1998) Effects of NiCl Toxicity on Stem Growth and Early Development in Triticum aestivum L. Phytomorphology, 38, 21-27.

[25] Sharma, D.C. and Sharma, C.P. (1993) Chromium Uptake and Its Effects on Growth And biological Yield of Wheat. Cereal Research Communication, 21, 317-322.

[26] Koca, H., Bor, M., Ozdemir, F. and Türkan, I. (2007) The Effect of Salt Stress on Lipid Peroxidation, Antioxidative Enzymes and Proline Content of Sesame Cultivars. Environmental and Experimental Botany, 60, 344-351. http://dx.doi.org/10.1016/j.envexpbot.2006.12.005

[27] Turan, M.A., Elkarim, A.H.A., Taban, N. and Taban, S. (2009) Effect of Salt Stress on Growth, Stomatal Resistance, Proline and Chlorophyll Concentrations on Maize Plant. African Journal of Agricultural Research, 4, 893-897.

[28] Aspinall, D. and Paleg, L.G. (1981) Proline Accumulation: Physiological Aspects, In: Paleg, L.G. and Aspinall, D. Eds., The Physiology and Biochemistry of Drought Resistance in Plants, Academic Press, Sydney, 205-241.

[29] Delauney, A.J. and Verna, D.P.S. (1993) Proline biosynthesis and osmoregulation in plants. Plant Journal, 4, $215-223$. http://dx.doi.org/10.1046/j.1365-313X.1993.04020215.X

[30] Hare, P.D., Cress, W.A. and Staden, J.V. (1999) Proline Synthesis and Degradation: A Model System for Elucidating Stress-Related Signal Transduction. Journal of Experimental Botany, 50, 413-434.

[31] Mansour, M.M.F. (2000) Nitrogen Containing Compounds and Adaptation of Plants to Salinity Stress. Plant Biology, 43, 491-500. http://dx.doi.org/10.1023/A:1002873531707

[32] Mohanty, S.K. and Sridhar, R. (1982) Physiology of Rice Tungro Virus Disease: Proline Accumulation Due to Infection. Plant Physiology, 56, 89-93. http://dx.doi.org/10.1111/j.1399-3054.1982.tb04904.x

[33] Mumtaz, S., Naqvi, S.S.M., Shereen, A. and Khan, M.A. (1995) Proline Accumulation in Wheat Seedlings Subjected to Various Stresses. Acta Plant Physiology, 17, 17-20.

[34] McGrath, S.P. (1998) Phytoextraction for Soil Remediation. In: Brooks, R.R., ed., Plants That Hyperaccumulate Heavy Metals: Their Role in Phytoremediation, Microbiology, Archaeology, Mineral Exploration and Phytomining. CAB International, New York, 261-288.

[35] Brown, S.L., Chancy, R.L., Angle, J.S. and Baker, A.J.M. (1995) Zinc and Cadmium Uptake by Hyperaccumulator Thlaspi caerulescens Grown in Nutrient Solution. Soil Science Society of America Journal, 59, 125-133. http://dx.doi.org/10.2136/sssaj1995.03615995005900010020x 